\title{
Dietary changes in migrant adolescents with increasing length of stay in Australia and associated risk of wheeze - a retrospective, cross sectional study
}

Lisa G. Wood ${ }^{1 *}$, Marivic Lagleva², Smita Shah², Bronwyn S. Berthon', Sally Galbraith ${ }^{3}$, Richard Henry ${ }^{4}$, Helen Kepreotes ${ }^{5}$ and Peter G. Gibson ${ }^{1,6}$

\begin{abstract}
Background: Recent studies have reported that asthma prevalence increases on migration to Australia. We hypothesised that changes in dietary intake contribute to this phenomenon. The aim of this study was to assess dietary intake in relation to migration status, length of stay in Australia and the association with self-reported wheeze.

Methods: Students ( $n=144$ ) in a multicultural high school in Western Sydney completed the asthma symptoms ISAAC video questionnaire (AVQ3.0), spirometry and allergy skin prick tests. A dietitian administered a'Food Frequency' and 'Food Habits' questionnaire and a dietary history interview.

Results: Students who spoke a language other than English, consumed a traditional or mixed dietary pattern, with lower consumption of saturated fat, compared to students who spoke English only. Saturated fat intake increased and fibre intake decreased with length of time in Australia. Intake of foods high in saturated or trans fatty acids were positively associated with length of stay in Australia. No associations between nutrient intake or whole food intake and self-reported wheeze were observed.
\end{abstract}

Conclusion: As time progressed, dietary intake of immigrant children changed. While this was not associated with the development of wheeze in the students in this cohort, these changes are likely to have negative health consequences.

Keywords: Paediatrics, Migration, Nutrition, Saturated fat, Fibre

\section{Background}

The prevalence of asthma in Australian children is one of the highest in the world, as reported by the International Study of Asthma and Allergies in Childhood (ISAAC) [1]. The National Health Survey (NHS) 2004-5 found that asthma is the most common chronic health condition in Australian children, with $20.8 \%$ of those aged 0 to 15 years having ever been diagnosed with asthma [2]. The Longitudinal Study of Australian Children (LSAC) followed a cohort of 4-5 year olds and showed that having wheeze or asthma doubled the risk

\footnotetext{
* Correspondence: Lisa.Wood@newcastle.edu.au

${ }^{1}$ Centre for Asthma and Respiratory Diseases, Hunter Medical Research Institute, University of Newcastle, Newcastle, New South Wales, Australia Full list of author information is available at the end of the article
}

of hospitalisation or frequent general practice visits for any cause and of reporting fair to poor health status over the next 2 years [3]. Elucidating the causes behind the higher asthma prevalence in Australia may provide insight into how the risk of asthma in children could be modified. As asthma is increasingly being recognised as a multifactorial condition, social, environmental and genetic factors are currently under investigation for their role in the development and progression of asthma and allergies [4]. A useful avenue of exploring both social and environmental exposures in relation to asthma risk is through the study of international immigrants [5]. Upon arrival migrant populations show different patterns of disease prevalence in comparison to the population of their new country of residence, though these 
differences usually disappear over time [6]. Migration studies show that when adolescents from countries with lower asthma prevalence rates migrate to Australia, their prevalence of asthma symptoms is significantly higher than their country of origin [7]. A Melbourne study of 51 high schools $(n=9778)$ found that migrant students that had stayed in Australia for 5-9 years and 10-14 years compared to those that had stayed 0-4 years had an increased chance of reporting wheeze [8]. Another Melbourne study found that the prevalence of asthma in Asian immigrants $(n=636)$ increased significantly with the length of stay in Australia [9]. We have previously reported that the prevalence of wheeze at rest was lower amongst adolescents who were recent migrants to Australia compared to those who had lived in Australia since birth [7].

Understanding the changes in environmental exposures of recent migrants may increase our understanding of the mechanisms behind the increased risk of asthma symptoms associated with migration.

Dietary patterns and nutrient intake are now recognised as a significant environmental exposure that may impact on asthma risk [10]. A number of recent reviews have examined the hypothesis that dietary changes, including decreasing antioxidant intake, decreasing n-3 polyunsaturated fat intake and increasing consumption of saturated and trans fatty acids are linked to increasing asthma prevalence [11-13]. The ISAAC phase 2 crosssectional study consisting of 20 countries and over 50 000 school children aged 8-12 years, recently reported that fish consumption in affluent countries was associated with decreased wheeze, a common symptom of asthma. Fruit and cooked vegetables consumption in non-affluent countries was also associated with decreased wheeze. Furthermore, burger consumption of greater than 3 times per week compared to never or occasionally was associated with an increased risk of ever having asthma. In contrast, raw green vegetable intake greater than 3 times per week compared to never or occasionally was associated with a decreased risk in ever having asthma [14]. The ISAAC phase 3 study analysed data from over $300000 \mathrm{ad}-$ olescents (13-14 years old) from 107 centres from 51 countries and over 180000 children (6-7 years old) from 64 centres from 31 countries. They consistently found for both age groups that an increased risk of severe asthma, rhino conjunctivitis and eczema is associated with greater than 3 times per week consumption of fast food. In contrast, greater than 3 times per week consumption of fruit is associated with a decreased risk of severe asthma, rhino conjunctivitis and eczema [15].

We hypothesised that changes in dietary intake occur in adolescents following arrival in Australia, which may be related to the development of asthma symptoms in some individuals. The aim of this study was to perform a retrospective analysis of cross-sectional data to investigate differences in dietary intake in immigrant children compared to non-immigrants, whether dietary intake changes with length of stay in Australia and whether these changes in dietary intake are related to self-reported wheeze with increasing length of stay in Australia.

\section{Methods \\ Study design}

We conducted a retrospective, cross-sectional nested study of a larger study of asthma symptoms and airway inflammation previously described [7, 16]. Adolescent subjects, aged $12-18$ years, were recruited from a multicultural high school in Western Sydney, Australia, in 1997 and 1998. The high school was chosen as it has one of the highest rates of recent migrant and refugee student enrolments in Sydney, NSW, Australia. The school has an Intensive English Centre to assist students from nonEnglish speaking backgrounds to learn English. All students in the high school were invited to participate, and all students completed the ISAAC video questionnaire. The participation rate in the original study was $78 \% .271$ students were approached, and 211 completed full asthma assessment. Of the 262 students who completed the ISAAC questionnaire, 144 students completed the dietary component.

This study includes the subset of subjects $(n=144,55 \%$ of all the subjects in the original study) for whom dietary records were available. Asthma symptoms including selfreported wheeze were recorded using the validated ISAAC video questionnaire, version 3.0 (AVQ3.0) [17] which consists of five video sequences of young people with different asthma symptoms. The first three sequences show various scenes of wheezing, while the final two sequences display other asthma symptoms. The scenes depicted: 1) moderate wheezing at rest (a Caucasian girl); 2) wheezing after exercise (a Maori boy); 3) waking at night with wheezing (a Caucasian girl); 4) waking at night with coughing (an Asian boy); and 5) a severe attack of asthma with wheezing and breathlessness at rest (an Indian woman). After each video sequence, students recorded on a one-page printed answer sheet whether their breathing had ever been like that shown in the video and, if so, the frequency of such symptoms (past month, past year, ever). The video questionnaire took about $7 \mathrm{~min}$ to administer, and the term "asthma" was not mentioned during this time. The questionnaire was presented to students by an ethnic healthcare worker who was based at the school. The child was asked to complete the questionnaire and to ask for clarification if required. When assistance was requested by the student, this was provided in both English and in the native language of the student.

Students completed an asthma medication questionnaire, and underwent spirometry and allergy skin prick 
Table 1 Subject characteristics

\begin{tabular}{|c|c|}
\hline N & 144 \\
\hline $\mathrm{Age}^{\mathrm{a}}$ & $13.6(12.8-15.2)$ \\
\hline Sex (\%Males) & 53.5 \\
\hline BMI $\left(\mathrm{kg} / \mathrm{m}^{2}\right)$ & $20.2(18.1-22.8)$ \\
\hline $\mathrm{FEV}_{1}, \mathrm{~L}$ & $2.85(2.40-3.40)$ \\
\hline FVC, L $(n=116)$ & $3.18(2.79-3.80)$ \\
\hline $\mathrm{FEV}_{1} / \mathrm{FVC}(n=116)$ & $0.90(0.85-0.95)$ \\
\hline DRS (\%fall/mL) & $0.22(0.07-0.44)$ \\
\hline Asthma Symptoms (\%Yes) & 28.5 \\
\hline Atopy (\%Yes) & 51.4 \\
\hline Wheeze (\%Yes) & 24.3 \\
\hline Asthma medication usage (\%Yes) ${ }^{b}$ & 12.5 \\
\hline Years in Australia & $3.0(0.7-12.3)$ \\
\hline Language (\%English only) & 34.7 \\
\hline
\end{tabular}

BMI Body mass index, FEV1 forced expiratory volume in $1 \mathrm{~s}$; FVC forced vital capacity; DRS dose response slope

${ }^{a}$ All data are presented as Median (IOR) unless otherwise stated. ${ }^{b}$ Asthma medications include: Alupent, Asmol, Atrovent, Becloforte, Becotide, Bricanyl, Flixotide, Pulmicorte, Respolin, Serevent, Theophylline, Ventolin

tests. Forced expiratory volume in one second $\left(\mathrm{FEV}_{1}\right)$ and forced vital capacity (FVC) were performed by wearing nose clips in the seated position using a dry wedge spirometer (Vitalograph, Buckingham, UK), and the best of three readings was recorded.

Skin prick tests were performed on the volar aspect of the forearm, using cat fur, grass mix, Alternaria tenuis, whole egg, cow's milk, Dermatophagoides farinae, Dermatophagoides pteronyssinus and cockroach (Bayer, Australia Ltd.). Positive (histamine $1 \%$ ) and negative (50\% glycerine) controls were used. A positive reaction was defined as a 3-mm or greater wheal diameter
15 min after skin prick. Permission to conduct this research was obtained from the Department of Schools Education and the Hunter Area Health Service and University of Newcastle Research Ethics Committees. Written informed consent was obtained from parents and students.

\section{Dietary assessment tools}

The data collection period was from October to December 1998. A 50 min interviewer administered questionnaire was conducted by a dietitian. Interpreters were used for 38 ( $25 \%)$ of the subjects interviewed. The nationality, language spoken other than English and the number of years lived in Australia, were recorded.

The diet history method [18] was used to record the usual weekly meal and snack consumption. Food intake was quantified using metric cup and spoon measures, a ruler to indicate dimensions of certain foods, photographs of commercial foods, typical household measures such as plates and bowls as well as three dimensional plastic food models. The food frequency qualitative questionnaire was intended to establish food consumption habits and was based on that used in the 1995 National Nutrition Survey [19]. Respondents were asked how often they consumed 107 food and drink items and 11 vitamin and mineral supplements over the past 12 months by estimating frequency of consumption. In addition there were 13 questions on dietary habits relating to fruit, vegetable, salt, fish and reduced fat dairy consumption. Nutrient intake was calculated using the software program DIET/1(version 4.00, 1997; Xyris Software, Brisbane, Queensland, Australia) which used the Australian NUTTAB 95 food composition database [20].

Table 2 Regression analysis examining the association between nutrient intake (as outcome) and immigrant status classified according to language spoken at home (language other than English $n=94$, or English only $n=56$ ) (as predictor), adjusted for age and sex

\begin{tabular}{|c|c|c|c|c|c|c|}
\hline Nutrient intake & $\begin{array}{l}\text { Unadjusted } \beta \text {-coefficient } \\
(n=144)\end{array}$ & $95 \% \mathrm{Cl}$ & $P$ & $\begin{array}{l}\beta \text {-coefficient adjusted for age and sex } \\
(n=138)\end{array}$ & $95 \% \mathrm{Cl}$ & $P$ \\
\hline \multicolumn{7}{|l|}{ Antioxidants } \\
\hline Carotene (ug) & 982.3 & $371.8-1592.7$ & 0.002 & 1109.5 & $433.6-1785.9$ & 0.001 \\
\hline Retinol equivalents (ug) & 173.3 & $18.1-328.5$ & 0.029 & 182.9 & $11.5-354.3$ & 0.037 \\
\hline Vitamin C (mg) & -31.4 & $-68.7-5.9$ & 0.099 & -40.1 & $-80.3-0.1$ & 0.051 \\
\hline \multicolumn{7}{|l|}{ Dietary fat } \\
\hline Total fat (g) & -9.3 & $-23.0-4.5$ & 0.186 & -13.1 & $-28.1-1.9$ & 0.088 \\
\hline$\%$ Saturated fat ${ }^{a}$ & 1.6 & $0.5-2.7$ & 0.006 & 1.1 & $-0.1-2.3$ & 0.072 \\
\hline$\%$ Monounsaturated fat ${ }^{a}$ & 0.3 & $-0.6-1.1$ & 0.552 & 0.3 & $-0.6-1.2$ & 0.545 \\
\hline \%Polyunsaturated fat ${ }^{a}$ & 0.3 & $-0.04-0.7$ & 0.084 & 0.3 & $-0.1-0.7$ & 0.153 \\
\hline \multicolumn{7}{|l|}{ Other } \\
\hline Fibre (g) & -3.6 & & 0.022 & -3.3 & & 0.055 \\
\hline
\end{tabular}

${ }^{\mathrm{a}}$ Expressed as a percentage of total energy intake 
Table 3 Regression analysis examining the association between whole food intake (as outcome) and immigrant status classified according to language spoken at home (Language other than English or English only) (as predictor), adjusted for age and sex

\begin{tabular}{|c|c|c|c|c|c|c|}
\hline Whole food intake (serves/day) & $\begin{array}{l}\text { Unadjusted } \beta \text {-coefficient } \\
(n=144)\end{array}$ & $95 \% \mathrm{Cl}$ & $P$ & $\begin{array}{l}\beta \text {-coefficient adjusted for } \\
\text { age and sex }(n=144)\end{array}$ & $95 \% \mathrm{Cl}$ & $P$ \\
\hline \multicolumn{7}{|l|}{ Foods high in Antioxidants } \\
\hline Fruit & -0.1 & $-0.3-0.2$ & 0.477 & -0.1 & $-0.3-0.2$ & 0.558 \\
\hline Nuts & 0.02 & $-0.1-0.1$ & 0.585 & 0.01 & $-0.1-0.1$ & 0.920 \\
\hline Tea & -0.2 & $-0.3-0.01$ & 0.060 & -0.1 & $-0.3-0.1$ & 0.297 \\
\hline \multicolumn{7}{|l|}{ Foods high in Saturated/Trans fats } \\
\hline Takeaway & -0.01 & $-0.1-0.02$ & 0.430 & -0.03 & $-0.1-0.01$ & 0.174 \\
\hline Pies & 0.1 & $-0.01-0.1$ & 0.111 & 0.03 & $-0.1-0.1$ & 0.451 \\
\hline Chocolate & 0.1 & $-0.1-0.2$ & 0.404 & 0.1 & $-0.1-0.2$ & 0.353 \\
\hline Cake & 0.2 & $0.1-0.4$ & 0.009 & 0.2 & $-0.01-0.3$ & 0.058 \\
\hline Ice cream & 0.1 & $-0.05-0.2$ & 0.258 & 0.03 & $-0.1-0.2$ & 0.670 \\
\hline Crisps & 0.2 & $0.05-0.3$ & 0.009 & 0.2 & $0.03-0.3$ & 0.021 \\
\hline \multicolumn{7}{|l|}{ Foods high in omega-3 fats } \\
\hline Fish & -0.01 & $-0.1-0.1$ & 0.872 & -0.027 & $-0.1-0.04$ & 0.421 \\
\hline
\end{tabular}

Take away food and snack food practices were also noted. The supervisor of the school canteen was contacted to obtain lists of menus, recipes and to inspect available food products. Dietary patterns were assessed by the dietitian as traditional, mixed and westernised. The definition for a traditional diet was high intake of fruits, vegetables and wholegrains with low intakes of red meat. The definition of a mixed dietary pattern was that the student ate traditional food at home but westernised food at school and frequently consumed takeaway foods. A westernised diet was defined as high in processed foods such as refined sugars, refined vegetable oils and fatty meats.

\section{Statistical analysis}

Group comparisons were made using Mann-Whitney tests for continuous variables and Pearson's chi-squared test for categorical variables. Multiple linear regression was used to do analyses of English language grouping association with nutrient or whole food intake adjusted for sex and age. Multiple linear regression was applied to explore associations between the intake of whole foods or nutrients and years living in Australia, while adjusting for control variables age and sex. Multiple logistic regression was applied to explore associations between vegetable intake and years living in Australia and between wheeze and dietary intake, while adjusting for years lived in Australia, age and sex. All exploratory analyses were carried out with the statistical program software R version 2.12.1.

\section{Results}

\section{Subject characteristics}

Data were analysed from a total of 144 high school students from whom both asthma symptoms and dietary data were available. Subject characteristics are summarised in Table $1.24 .3 \%$ of subjects had wheeze at rest. The median interquartile range (IQR) time of residence in Australia was $3(0.7-12.3)$ years and $65 \%$ spoke another language other than English. The students came from 30 different countries that were collapsed into regions. The nationalities represented in the school were Middle Eastern 57/ 144 (40 \%), Australian 40/144 (28 \%), Asian 26/144 (18 \%) and other mixed nationalities 21/144 (15\%).

Table 2 describes the results of a regression analysis examining the association between nutrient intake and immigrant status classified according to language spoken at home. Both carotene and retinol equivalent intake was higher for the English only speaking students. Vitamin $\mathrm{C}$ intake tended to be higher for those that spoke a language other than English and this was borderline significant. Fibre intake tended to be lower in the English only speaking students and this was also borderline statistically significant.

Table 4 Frequencies between dietary intake and immigrant status classified according to language spoken at home (Language other than English or English only) $(n=138)$

\begin{tabular}{lccc}
\hline Vegetable intake & $\begin{array}{l}\text { Language other than English } \\
(n=88)\end{array}$ & $\begin{array}{c}\text { English only } \\
(n=50)\end{array}$ & $P$ \\
\hline 0.5 serves/day & $67(76)$ & $34(48)$ & 0.403 \\
$>0.5$ serves/day & $21(24)$ & $16(32)$ & \\
Dietary Pattern & & & \\
Traditional & $27(31)$ & $2(4)$ & $<0.001$ \\
Mixed & $58(66)$ & $7(14)$ & \\
Westernised & $3(3)$ & $41(82)$ & \\
\hline
\end{tabular}

Data presented as $\mathrm{n}(\%)$ 
Table 5 Regression analysis examining the association between nutrient intake (outcome) and length of time in Australia (predictor)

\begin{tabular}{|c|c|c|c|c|c|c|}
\hline Nutrient intake & $\begin{array}{l}\text { Unadjusted } \beta \text {-coefficient } \\
(n=144)\end{array}$ & $95 \% \mathrm{Cl}$ & $P$ & $\begin{array}{l}\beta \text {-coefficient adjusted for } \\
\text { age and sex }(n=144)\end{array}$ & $95 \% \mathrm{Cl}$ & $P$ \\
\hline \multicolumn{7}{|l|}{ Antioxidants } \\
\hline Carotene (ug) & 67.6 & $16.0-119.2$ & 0.011 & 77.8 & $19.5-136.0$ & 0.009 \\
\hline Retinol equivalents (ug) & 12.5 & $-0.4-25.5$ & 0.058 & 15.4 & $0.9-29.9$ & 0.037 \\
\hline Vitamin C (mg) & 0.2 & $-2.9-3.2$ & 0.909 & -0.6 & $-4.03-2.7$ & 0.706 \\
\hline \multicolumn{7}{|l|}{ Dietary fat } \\
\hline Total fat (g) & -0.6 & $-1.7-0.6$ & 0.318 & -0.6 & $-1.9-0.6$ & 0.325 \\
\hline$\%$ Saturated fat ${ }^{\mathrm{a}}$ & 0.1 & $0.1-0.2$ & 0.002 & 0.1 & $0.02-0.2$ & 0.021 \\
\hline \%Monounsaturated fat ${ }^{a}$ & 0.01 & $-0.1-0.1$ & 0.733 & 0.01 & $-0.1-0.1$ & 0.752 \\
\hline \%Polyunsaturated fat ${ }^{\mathrm{a}}$ & 0.01 & $-0.02-0.03$ & 0.664 & 0.003 & $-0.03-0.04$ & 0.874 \\
\hline \multicolumn{7}{|l|}{ Other } \\
\hline Fibre (g) & -0.3 & $-0.6--0.1$ & 0.013 & -0.3 & $-0.6--0.1$ & 0.021 \\
\hline
\end{tabular}

${ }^{a}$ Expressed as a percentage of total energy intake

Tables 3 and 4 describe the results of a regression analysis examining the association between whole dietary intake and immigrant status classified according to language spoken at home. Some whole foods high in saturated fat such as crisps and cake were consumed at higher levels in those that spoke English only. Of those that spoke a language other than English, more students consumed a traditional or mixed dietary pattern, while in the only English speaking group, more students consumed a westernised dietary pattern.

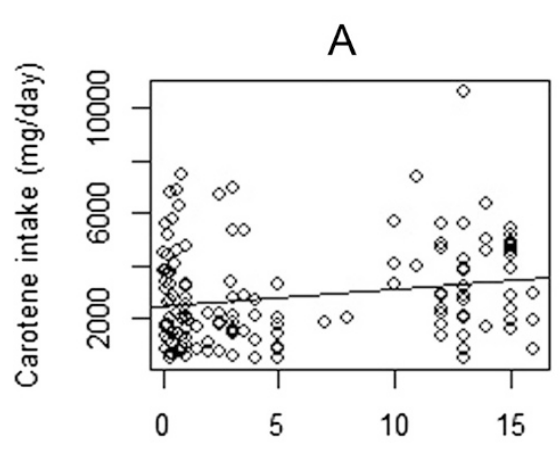

Residence time in Australia (Years)

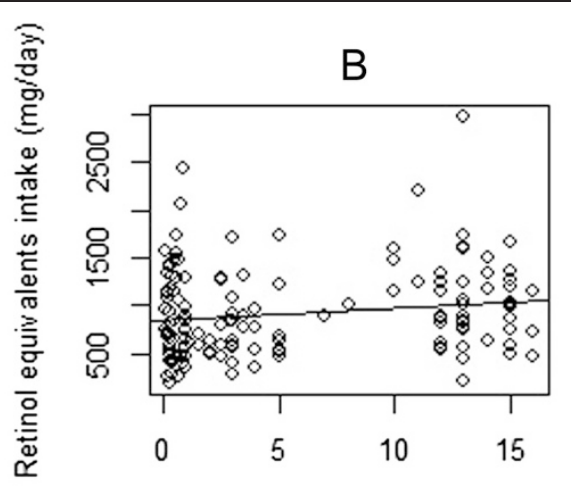

Residence time in Australia (Years)

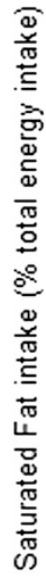

\section{C}

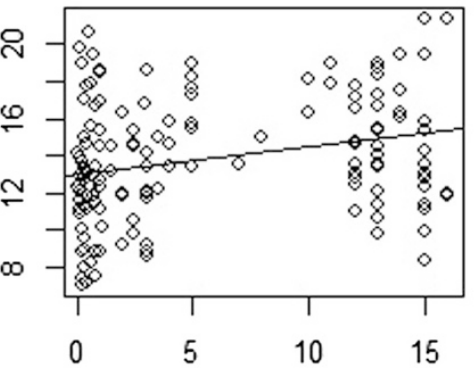

Residence time in Australia (Years)

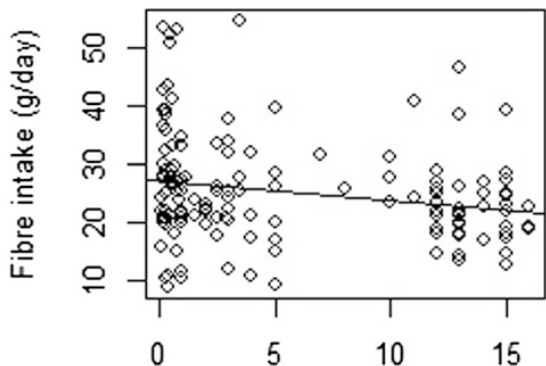

Residence time in Australia (Years)

Fig. 1 Correlation between length of time in Australia and nutrient intake, including a Carotene (coefficient $=67.630 \mathrm{p}$-value $=0.01$ ), b Retinol equivalents (coefficient $=12.531$-value $=0.058), \mathbf{c} \%$ Saturated Fat (coefficient $=0.146 p$-value $=0.002)$ and $\mathbf{d}$ Fibre $($ coefficient $=0.324 p$-value $=0.013$ ) 
Table 6 Regression analysis examining the association between whole food intake (outcome) and length of time in Australia (predictor)

\begin{tabular}{|c|c|c|c|c|c|c|}
\hline Whole food intake (serves/day) & $\begin{array}{l}\text { Unadjusted } \beta \text {-coefficient } \\
(n=144)\end{array}$ & $95 \% \mathrm{Cl}$ & $P$ & $\begin{array}{l}\beta \text {-coefficient adjusted for } \\
\text { age and sex }(n=144)\end{array}$ & $95 \% \mathrm{Cl}$ & $P$ \\
\hline \multicolumn{7}{|l|}{ Foods high in Antioxidants } \\
\hline Fruit & 0.01 & $-0.01-0.03$ & 0.269 & 0.01 & $-0.01-0.03$ & 0.318 \\
\hline Nuts & 0.002 & $-0.01-0.01$ & 0.602 & -0.001 & $-0.01-0.01$ & 0.842 \\
\hline Tea & -0.02 & $-0.03--0.01$ & 0.008 & -0.01 & $-0.03-0.003$ & 0.131 \\
\hline \multicolumn{7}{|l|}{ Foods high in Saturated/Trans fats } \\
\hline Takeaway & 0.001 & $-0.003-0.004$ & 0.687 & -0.0001 & $-0.004-0.003$ & 0.916 \\
\hline Pies & 0.01 & $0.002-0.02$ & 0.009 & 0.01 & $0.001-0.015$ & 0.041 \\
\hline Chocolate & 0.01 & $-0.003-0.02$ & 0.146 & 0.01 & $-0.01-0.02$ & 0.339 \\
\hline Cake & 0.02 & $0.004-0.03$ & 0.010 & 0.01 & $-0.003-0.02$ & 0.125 \\
\hline Ice cream & 0.01 & $-0.001-0.02$ & 0.099 & 0.01 & $-0.01-0.02$ & 0.377 \\
\hline Crisps & 0.02 & $0.01-0.03$ & $<0.001$ & 0.02 & $0.01-0.03$ & 0.003 \\
\hline \multicolumn{7}{|l|}{ Foods high in omega-3 fats } \\
\hline Fish & 0.003 & $-0.001-0.01$ & 0.158 & 0.002 & $-0.004-0.01$ & 0.511 \\
\hline
\end{tabular}

Table 5 describes the association between nutrient intake and time residing in Australia. Carotene and retinol equivalents showed a positive association with time in Australia that persisted after adjusting for age and sex [Fig. 1a and b]. No association was found with vitamin C. Saturated fat intake increased as length of time in Australia increased and this association remained after controlling for age and sex [Fig. 1c]. Conversely, fibre intake decreased with increasing length of stay in Australia in both the unadjusted and adjusted models [Fig. 1d]. In the analysis of whole foods (Tables 6 and 7), foods high in saturated or trans fatty acids were positively associated with time in Australia, including pies, cakes and crisps. After adjustment for age and sex, pies and crisps remained significantly positively associated with time in Australia. Figure 2 demonstrates that dietary pattern was associated with time in Australia. No associations between nutrient intake or whole food

Table 7 Frequencies of dietary intake and categories of length of time in Australia $(N=144)$

\begin{tabular}{lcccc}
\hline \multirow{4}{*}{ Vegetable intake } & \multicolumn{2}{l}{ Time in Australia } & & \\
\cline { 2 - 4 } & $\begin{array}{l}<=2 \text { years } \\
(n=61)\end{array}$ & $\begin{array}{l}>2 \text { years, } \\
(n=38)\end{array}$ & $\begin{array}{c}\text { Lifetime } \\
(n=45)\end{array}$ & $P$ \\
\hline 0.5 serves/day & $50(82)$ & $24(63)$ & $41(91)$ & 0.094 \\
$>0.5$ serves/day & $11(18)$ & $14(37)$ & $4(9)$ & \\
Dietary Pattern & & & & \\
Traditional & $28(46)$ & $3(8)$ & $1(2)$ & \\
Mixed & $33(54)$ & $31(82)$ & $4(9)$ & $N^{a}$ \\
Westernised & 0 & $4(10)$ & $40(89)$ & \\
\hline
\end{tabular}

${ }^{a}$ Not Available as a p-value cannot be obtained with the chi-squared test for a cell having zero value intake and self-reported wheeze were observed (Tables 8, 9 and 10).

\section{Discussion}

In our cross-sectional analysis we have described the differences in dietary intake in Australian households which speak a language other than English, compared to English-only speaking households. We have demonstrated that those households who spoke a language

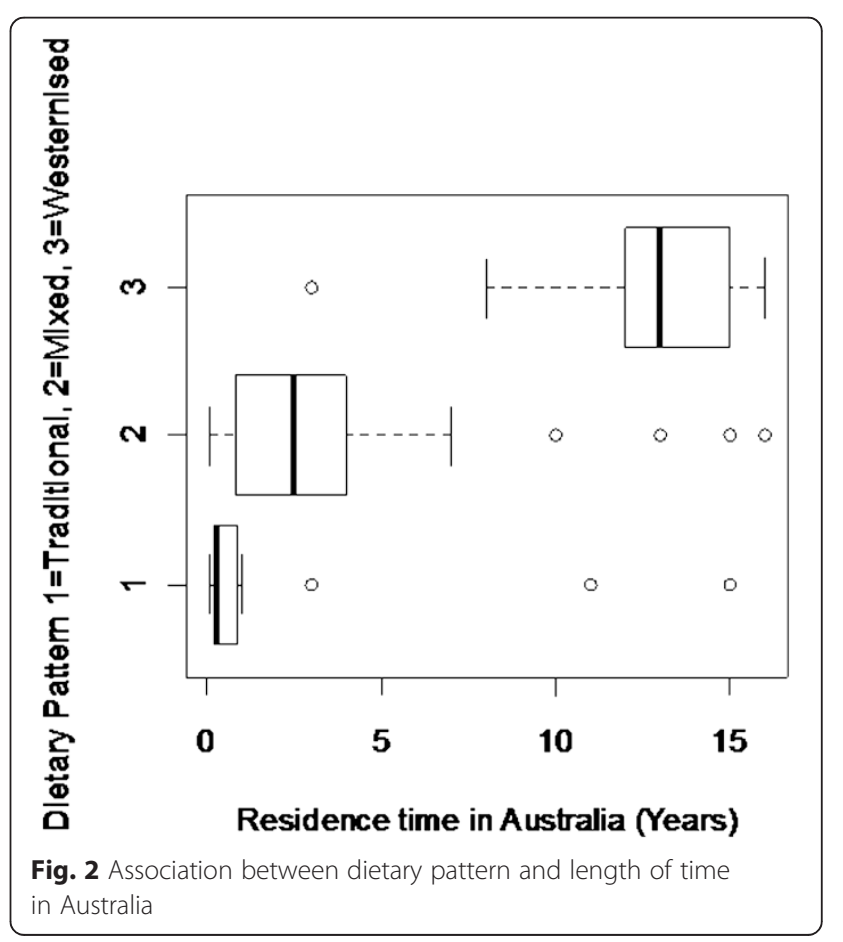


Table 8 Logistic regression analysis examining the association between wheeze (outcome) and nutrient intake (predictor)

\begin{tabular}{|c|c|c|c|c|c|c|}
\hline Nutrient intake & Unadjusted odds ratio $(n=144)$ & $95 \% \mathrm{Cl}$ & $P$ & Adjusted $^{\mathrm{b}}$ odds ratio $(n=144)$ & $95 \% \mathrm{Cl}$ & $P$ \\
\hline \multicolumn{7}{|l|}{ Antioxidants } \\
\hline Carotene (ug) & 1.0 & $1.0-1.0$ & 0.930 & 1.0 & $1.0-1.0$ & 0.555 \\
\hline Retinol equivalents (ug) & 1.0 & $1.0-1.0$ & 0.829 & 1.0 & $1.0-1.0$ & 0.743 \\
\hline Vitamin C (mg) & 1.0 & $1.0-1.0$ & 0.090 & 1.0 & $1.0-1.0$ & 0.063 \\
\hline \multicolumn{7}{|l|}{ Dietary fat } \\
\hline Total fat (g) & 1.0 & $1.0-1.0$ & 0.347 & 1.01 & $1.0-1.0$ & 0.217 \\
\hline$\%$ Saturated fat ${ }^{a}$ & 1.1 & $1.0-1.2$ & 0.244 & 1.04 & $0.9-1.2$ & 0.593 \\
\hline$\%$ Monounsaturated fat ${ }^{a}$ & 1.1 & $1.0-1.3$ & 0.117 & 1.2 & $1.0-1.4$ & 0.111 \\
\hline \%Polyunsaturated fat ${ }^{a}$ & 0.9 & $0.6-1.3$ & 0.623 & 0.9 & $0.6-1.3$ & 0.535 \\
\hline \multicolumn{7}{|l|}{ Other } \\
\hline Fibre (g) & 1.0 & $0.9-1.0$ & 0.468 & 1.0 & $1.0-1.0$ & 0.853 \\
\hline
\end{tabular}

Expressed as a percentage of total energy intake, ${ }^{\mathrm{b}}$ Adjusted for age, sex and length of time in Australia

other than English, consumed a traditional or mixed dietary pattern, with lower intake of foods containing saturated fat. We have also shown that dietary changes occur over time when adolescents migrate from a developing country to a western country, with increased consumption of saturated fat and decreased intake of fibre. This was driven by an increase in fast-foods including pies and crisps. Contrary to our hypothesis, no associations between nutrient intake or whole food intake and self-reported wheeze were observed.

The consequence of the changes in dietary pattern that we observed in newly arrived migrant students is the potential exposure to several pro-inflammatory nutrients. Dietary fat, in particular saturated fatty acids, can activate an innate immune response, involving activation of Toll- like receptors, which are cell surface receptors that are traditionally known to be activated by bacteria [13]. As a result, an inflammatory cascade is initiated, involving activation of the transcription factor $\mathrm{NF}_{\mathrm{B}} \mathrm{B}$ and increased expression of pro-inflammatory cytokines such as IL-6 and TNF $\alpha$. Reduced intakes of fibre can also promote inflammation. A proposed mechanism involves butyrate, a short chain fatty acid (SCFA), produced as microbiota in the gut digest dietary fibre. This activates the peroxisome proliferator-activated receptor- $\alpha$ (PPAR $\alpha)$ which then inhibits NFкB activity [21]. SCFAs also interact with receptors from a family of $G$ protein-coupled receptors $[22,23]$. G protein-coupled receptor 43 (GPR43) activation by acetate, another SCFA produced by microbiota fermentation of fibre, caused apoptosis in neutrophils and

Table 9 Logistic regression analysis examining the association between wheeze (outcome) and whole food intake (predictor)

\begin{tabular}{|c|c|c|c|c|c|c|}
\hline Whole food intake & Unadjusted odds ratio $(n=144)$ & $95 \% \mathrm{Cl}$ & $P$ & Adjusted $^{\mathrm{a}}$ odds ratio $(n=144)$ & $95 \% \mathrm{Cl}$ & $P$ \\
\hline \multicolumn{7}{|c|}{ Foods high in Antioxidants } \\
\hline Fruit & 0.9 & $0.5-1.6$ & 0.635 & 0.9 & $0.5-1.6$ & 0.645 \\
\hline Nuts & 0.9 & $0.2-3.4$ & 0.680 & 0.8 & $0.2-3.5$ & 0.783 \\
\hline Tea & 1.0 & $0.4-2.2$ & 0.863 & 1.2 & $0.5-2.7$ & 0.705 \\
\hline \multicolumn{7}{|c|}{ Foods high in Saturated/Trans fats } \\
\hline Takeaway & 0.2 & $0.01-6.2$ & 0.129 & 0.1 & $0.002-6.1$ & 0.286 \\
\hline Pies & 0.9 & $0.2-4.8$ & 0.518 & 0.5 & $0.1-3.4$ & 0.479 \\
\hline Choc & 0.9 & $0.3-2.7$ & 0.597 & 0.8 & $0.2-2.6$ & 0.677 \\
\hline Cake & 1.4 & $0.6-3.2$ & 0.723 & 1.1 & $0.5-2.8$ & 0.777 \\
\hline Ice cream & 0.8 & $0.2-2.6$ & 0.559 & 0.6 & $0.2-2.2$ & 0.490 \\
\hline Crisps & 1.5 & $0.6-3.8$ & 0.583 & 1.1 & $0.4-3.0$ & 0.823 \\
\hline \multicolumn{7}{|c|}{ Foods high in omega-3 fats } \\
\hline Fish & 1.3 & $0.1-11.9$ & 0.843 & 0.980 & $0.1-11.2$ & 0.987 \\
\hline
\end{tabular}

${ }^{\mathrm{a}}$ Adjusted for age, sex and length of time in Australia 
Table 10 Frequencies of wheeze at rest and dietary intake

\begin{tabular}{lccc}
$(N=144)$ & & \\
\hline Vegetable intake & $\begin{array}{l}\text { Wheeze at rest }=\text { No } \\
(n=109)\end{array}$ & $\begin{array}{l}\text { Wheeze at rest = Yes } \\
(n=35)\end{array}$ & $P$ \\
\hline 0.5 serves/day & $81(74)$ & $24(69)$ & 0.665 \\
$>0.5$ serves/day & $28(26)$ & $11(31)$ & \\
Dietary Pattern & & $6(17)$ & 0.355 \\
Traditional & $26(24)$ & $15(43)$ & \\
Mixed & $53(49)$ & $14(40)$ & \\
Westernised & $30(27)$ & &
\end{tabular}

reduced inflammatory responses in mice models of airway inflammation, further supporting the anti-inflammatory role of fibre [23].

This inflammatory environment may contribute to the development of various inflammatory diseases. Indeed, we hypothesised that the increased prevalence of wheeze on migration to a western country that we have previously reported in this cohort [7], may have been associated with these dietary changes. Intervention studies have shown that nutritional modulation affects asthma outcomes. For example, a high antioxidant diet reduced exacerbation risk and improved lung function compared to a low antioxidant diet [24]. Conversely, a high-fat meal can worsen airway inflammation in asthma [25]. A number of population-based studies have also shown associations between western diets (including reduced fruit and vegetable intake, increased intake of fat, processed foods and fast foods) and increased asthma risk in children [26-28]. Furthermore, children who reported eating fruit more than once a day had higher lung function than children who reported never eating fruit [29]. We have also reported an association between high fat and low fibre diets and worse airway inflammation and lung function in asthma [30]. It is important to acknowledge that while this data was collected some time ago, migration into Australia from developing countries continues to occur, thus people continue to be exposed to a different environment (including dietary intake) from their country of origin. We believe that these results are still relevant and are able to inform us that diet does change on migration and our results are able to explain the nature of the dietary change.

The observational study design employed in this investigation is limited to detecting associations, and as it was cross-sectional is only able to show a snapshot of dietary intake and asthma symptoms at one point in time. The data for this study was collected as part of a previously conducted larger study. Not all students in the original study completed the dietary assessment reported in this study, thus a full data set was available for $55 \%$ of the original study population. This could introduce bias and limit the generalisability of the results, though the extent of this is unknown. While our analysis didn't identify an association between self-reported wheeze and dietary changes in immigrant children, it is possible that the study was underpowered to detect such an association. The selection of this small sample is also subject to bias as it was limited to convenience sample of subjects who had provided both asthma symptoms and dietary data. Furthermore there is a potential for selection bias in that the dietary intakes of these subjects may not be completely representative of their population groups. Further investigation of this phenomenon in a larger cohort, also looking at trends in dietary intake over time is warranted. This study displays many strengths including the use of a diverse range of validated assessment tools, rigorous statistical analysis and access to a unique population.

\section{Conclusions}

In summary, this study has shown that dietary patterns and nutrient intake of adolescent migrants from a developing country differ to the host population. We have also elucidated the nature of the dietary change and concluded that these changes are likely to promote an inflammatory environment. While we didn't identify any association between dietary change and increased wheeze, it is likely that there will be negative health consequences arising from this type of change in food consumption, which should be monitored in other settings. Our study provides useful insight into the changes that occur upon migration and suggest that investigation of health and disease in migration may shed some light into the environmental risks associated with asthma and reasons behind discordant international asthma prevalence rates.

\section{Abbreviations}

BMI: Body mass index; DRS: Dose response slope; FEV1: Forced expiratory volume in $1 \mathrm{~s}$; FVC: Forced vital capacity; GPR43: G protein-coupled receptor 43; IQR: Interquartile range; ISAAC: International Study of Asthma and Allergies in Childhood; LSAC: The Longitudinal Study of Australian Children; NHS: The National Health Survey (NHS); PPARa: Peroxisome proliferatoractivated receptor-a; SCFA: Short chain fatty acid.

\section{Competing interests}

The authors declare that they have no competing interests.

\section{Authors' contributions}

SS, PGG and RH conceived the study design. HK coordinated the acquisition of data. ML, SG, SS and LW conducted the analysis and interpretation of data. PGG; SS, RH, ML, BSB, SG and LW have been involved in drafting the manuscript and revising it critically for important intellectual content. All authors read and approved the final manuscript.

\section{Acknowledgements}

We thank Professor Richard Beasley, the Wellington Asthma Research Group, and the ISAAC study team for providing the video questionnaire. We also thank Ruth Toneguzzi, Kellie Fakes, Fiona Collier, Robyn Hankin, Hassan Mamoon, Amanda Wilson, Anne Stuckey, Dr H Davies, Dr M Norzila, and $\operatorname{Dr} C$ Dakin for assistance with data collection. We acknowledge the cooperation of the students and teachers of Holroyd High School, and the assistance provided by the school principal Ms. Dorothy Hoddinott. No financial assistance was received for this study. 


\section{Author details}

${ }^{1}$ Centre for Asthma and Respiratory Diseases, Hunter Medical Research Institute, University of Newcastle, Newcastle, New South Wales, Australia. ${ }^{2}$ Primary Health Care Education and Research Unit, Western Clinical School and School of Public Health, University of Sydney, Sydney, New South Wales, Australia. ${ }^{3}$ School of Mathematics and Statistics, University of New South Wales, Sydney, New South Wales, Australia. ${ }^{4}$ University of New South Wales, Sydney, NSW, Australia. ${ }^{5}$ Department of Nutrition and Dietetics, Sydney Children's Hospital Network, Randwick Campus, Sydney, New South Wales, Australia. ${ }^{6}$ Department of Respiratory and Sleep Medicine, John Hunter Hospital, Kookaburra Circuit, New Lambton Heights, NSW 2305, Australia.

Received: 18 May 2014 Accepted: 17 August 2015

Published online: 26 August 2015

\section{References}

1. Beasley R, ISAAC Steering Committee. Worldwide variation in prevalence of symptoms of asthma, allergic rhinoconjunctivitis, and atopic eczema: ISAAC. The International Study of Asthma and Allergies in Childhood (ISAAC) Steering Committee. Lancet. 1998;351(9111):1225-32.

2. ACAM. Asthma in Australia 2008. Cat no. ACM 14. Canberra: AlHW; 2008

3. ACAM. Asthma in Australian children: findings from Growing Up in Australia, the Longitudinal Study of Australian Children. Cat. no. ACM 17. AlHW: Canberra; 2009

4. Cabieses B, Uphoff E, Pinart M, Anto JM, Wright J. A systematic review on the development of asthma and allergic diseases in relation to international immigration: the leading role of the environment confirmed. PLoS One. 2014;9(8):e105347.

5. D'Amato G, Rottem M, Dahl R, Blaiss M, Ridolo E, Cecchi L, et al. Climate Change, Migration, and Allergic Respiratory Diseases: An Update for the Allergist. World Allergy Org J. 2011;4(7):120-5.

6. Palloni A, Arias E. Paradox lost: explaining the Hispanic adult mortality advantage. Demography. 2004:41(3):385-415.

7. Gibson PG, Henry RL, Shah S, Powell H, Wang H. Migration to a western country increases asthma symptoms but not eosinophilic airway inflammation. Pediatr Pulmonol. 2003;36:209-15.

8. Powell CV, Nolan TM, Carlin JB, Bennett CM, Johnson PD. Respiratory symptoms and duration of residence in immigrant teenagers living in Melbourne. Australia Arch Dis Child. 1999:81(2):159-62

9. Leung R, Carlin J, Burdon J, Czarny D. Asthma, allergy and atopy in Asian immigrants in Melbourne. Medical J Aust. 1994;161(7):418-25.

10. Nurmatov $U$, Devereux $G$, Sheikh A. Nutrients and foods for the primary prevention of asthma and allergy: Systematic review and meta-analysis. J Allergy Clin Immunol. 2011:127(3):724-733.e730.

11. Devereux $G$, Seaton A. Diet as a risk factor for atopy and asthma. J Allergy Clin Immunol. 2005:115(6):1109-17.

12. McKeever T, Britton J. Diet and asthma. Am Journal Respir Crit Care Med. 2004:170(7):725-9.

13. Wood LG, Gibson PG. Dietary factors lead to innate immune activation in asthma. Pharmacol Ther. 2009;123(1):37-53.

14. Nagel G, Weinmayr G, Kleiner A, Garcia-Marcos L, Strachan DP. Effect of diet on asthma and allergic sensitisation in the International Study on Allergies and Asthma in Childhood (ISAAC) Phase Two. Thorax. 2010;65(6):516-22

15. Ellwood P, Asher MI, García-Marcos L, Williams H, Keil U, Robertson C, et al. Do fast foods cause asthma, rhinoconjunctivitis and eczema? Global findings from the International Study of Asthma and Allergies in Childhood (ISAAC) Phase Three. Thorax. 2013:68(4):351-60.

16. Thomas P, Gibson P, Wang H, Shah S, Henry R. The relationship of exhaled nitric oxide to airway inflammation and responsiveness in children. J Asthma. 2005;42(4):291-5.

17. Lai C, Chan J, Chan A, Wong G, Ho A, Choy D, et al. Comparison of the ISAAC video questionnaire (AVQ3.0) with the ISAAC written questionnaire for estimating asthma associated with bronchial hyperreactivity. Clin Exp Allergy. 1997;27:540-5.

18. Thompson FE. Dietary assessment resource manual. J Nutr. 1994;124(11 Suppl):2245S-317.

19. McLennan W, Podger A. National Nutrition Survey User's Guide 1995. 48010th ed. Canberra: Australian Bureau of Statistics; 1998

20. Lewis J, Milligan GC, Hunt A, National Food Authority (Australia). NUTTAB95 nutrient data table for use in Australia. Canberra: National Food Authority; 1995
21. Galisteo M, Duarte J, Zarzuelo A. Effects of dietary fibers on disturbances clustered in the metabolic syndrome. J Nutr Biochem. 2008;19(2):71-84.

22. Brown AJ, Jupe $S$, Briscoe CP. A family of fatty acid binding receptors. DNA Cell Biol. 2005;24(1):54-61.

23. Maslowski KM, Vieira AT, Ng A, Kranich J, Sierro F, Yu D, et al. Regulation of inflammatory responses by gut microbiota and chemoattractant receptor GPR43. Nature. 2009;461(7268):1282-6.

24. Wood LG, Garg ML, Smart JM, Scott HA, Barker D, Gibson PG. Manipulating antioxidant intake in asthma: a randomized controlled trial. Am J Clin Nutr. 2012;96(3):534-43.

25. Wood LG, Garg ML, Gibson PG. A high-fat challenge increases airway inflammation and impairs bronchodilator recovery in asthma. J Allergy Clin Immunol. 2011:127(5):1133-40.

26. Wickens K, Barry D, Friezema A, Rhodius R, Bone N, Purdie G, et al. Fast foods - are they a risk factor for asthma? Allergy. 2005:60(12):1537-41.

27. Huang SL, Lin KC, Pan WH. Dietary factors associated with physiciandiagnosed asthma and allergic rhinitis in teenagers: analyses of the first Nutrition and Health Survey in Taiwan. Clin Exp Allergy. 2001;31(2):259-64.

28. Hijazi N, Abalkhail B, Seaton A. Diet and childhood asthma in a society in transition: a study in urban and rural Saudi Arabia. Thorax. 2000;55(9):775-9.

29. Cook DG, Carey IM, Whincup PH, Papacosta O, Chirico S, Bruckdorfer KR, et al. Effect of fresh fruit consumption on lung function and wheeze in children. Thorax. 1997;52:628-33.

30. Berthon BS, Macdonald-Wicks LK, Gibson PG, Wood LG. An investigation of the association between dietary intake, disease severity and airway inflammation in asthma. Respirology. 2013;18(3):447-54

\section{Submit your next manuscript to BioMed Central and take full advantage of:}

- Convenient online submission

- Thorough peer review

- No space constraints or color figure charges

- Immediate publication on acceptance

- Inclusion in PubMed, CAS, Scopus and Google Scholar

- Research which is freely available for redistribution 